\section{Neonatal Lupus Erythematosus}

\author{
Nehad Nasef ${ }^{1,4 *}$, Mona Hafez ${ }^{2,4}$ and Ashraf Bakr ${ }^{3,4}$ \\ ${ }^{1}$ Neonatal Intensive Care Unit, Mansoura University Children's Hospital, \\ Mansoura, Egypt \\ ${ }^{2}$ Pediatric Cardiology Unit, Mansoura University Children's Hospital, \\ Mansoura, Egypt
}

${ }^{3}$ Pediatric Nephrology Unit, Mansoura University Children's Hospital, Mansoura, Egypt

${ }^{4}$ Department of Pediatrics, Faculty of medicine, University of Mansoura, Mansoura, Egypt

\begin{abstract}
Neonatal lupus is a passively acquired autoimmune disease that occurs in offspring of mothers with anti-SSA/Ro and/or anti-SSB/La antibodies. The primary clinical features are a photosensitive rash that is usually found on the scalp and periorbital areas, congenital heart block with or without cardiomyopathy, cytopenias, disseminated intravascular coagulation, and neonatal cholestasis with or without elevated transaminases. The diagnosis is usually made in utero by detection of a slow fetal heart rate and subsequent fetal echocardiographic confirmation of heart block and/or cardiomyopathy. Prenatal treatment with fluorinated glucocorticoids beginning as soon after detection has favourable outcome for mothers of fetuses with second degree heart block, is of no value for mothers of fetuses with third degree heart block, and controversial for mothers of fetuses with first degree heart block. Prenatal glucocorticoids can be used also in presence of cardiomyopathy associated with neonatal lupus. Hydroxychloroquine has been used in pregnant women who have anti-SSA/Ro antibodies and who have previously given birth to a child with cardiac manifestations. First and second degree block, detected in utero or at birth, can progress to complete heart block. Infants with complete heart block usually require a pacemaker with an excellent prognosis, although development of heart failure may occur.

Keywords: Lupus erythematosus; Neonatal lupus syndrome; Congenital heart block
\end{abstract}

\section{Abbreviations}

ADHD: Attention Deficit Hyperactivity Disorders; ANA: Antinuclear antibody; Anti-RNP: Anti-Ribonucleoprotein; APL: Antiphospholipid; CHB: Congenital heart block; CNS: Central Nervous System; IG: Immunoglobulin; IVIG: Intravenous immunoglobulin; NICU: Neonatal Intensive Care Unit; NLS: Neonatal lupus syndrome; SLE: Systemic lupus erythematosus; SSA/Ro: Anti-Sjogren's syndrome

*Corresponding author: Nehad Nasef, Department of Pediatrics, Faculty of medicine, University of Mansoura, Mansoura 35516, Egypt, Tel: +201001229299; E-mail: nehad_nasef@mans.edu.eg

Citation: Nasef N, Hafez M and Bakr A (2014) Neonatal Lupus Erythematosus. J Neonatol Clin Pediatr 1: 002

Received: July 01, 2014; Accepted: August 22, 2014; Published: September 05, 2014
A antibody (Anti-Ro antibody); SSB/La: Anti-Sjogren's syndrome B antibody (Anti-La antibody)

\section{Introduction}

Neonatal lupus erythematosus presents group of autoimmune disorders that results from either congenital trans-placental passage of antinuclear and ribonuclear autoantibodies targeting fetal and neonatal tissues (Neonatal Lupus Syndromes( or to less extent from infant's intrinsic deregulated immune system (Primary infantile SLE). Neonatal lupus syndromes (NLS) occurs in infants born to mother with rheumatic conditions including systemic lupus erythematous (SLE), Sjögren's disease, mixed connective tissue disease, leukocytoclastic vasculitis, various forms of arthritis, immune-mediated thrombocytopenia, thyroiditis, autoimmune hepatitis, and undifferentiated autoimmune syndromes. However, only $1 \%$ of infants with positive maternal autoantibodies develop neonatal lupus erythematosus and some cases are born to asymptomatic mothers who are unaware of their autoimmune disorders and get their sero-positivity discovered after an affected infant. Maternal disease activity during pregnancy has been associated with increased frequency of neonatal morbidities and admission to the NICU [1].

Congenital NLS presents mainly with cardiac, dermatologic, and hepatic manifestations and to less extent with hematologic, central nervous system, or splenic abnormalities. Primary infantile SLE frequently involves the kidneys, and requires aggressive immunosuppressive therapy.

\section{Epidemiology}

Neonatal lupus erythematosus is an uncommon disease described mainly in isolated case reports. Neonatal lupus erythematosus occurs in 1 of every 20,000 American live births and in 0.6 of every 100,000 children annually. The presence of human leukocyte antigen B8 (HLA-B8) and human leukocyte antigen DR3 (HLA-DR3) in the mother predisposes the infant to neonatal lupus erythematosus and congenital heart block. Lupus erythematosus of childhood appears to be more common in black, Latin American, and Asian children (3:1 ratio in all races compared with white patients). Female infants have two to three times' higher incidence for developing cardiac and cutaneous neonatal lupus erythematosus compared to male infants.

Congenital complete heart block, diagnosed by mid-trimester fetal echocardiography, was detected in $2 \%$ of first-observed pregnancies and $1.8 \%$ of live births to women with positive maternal screening for anti-SSA/Ro antibodies [2-4]. In a prospective study of 98 infants born to mothers with positive anti-SSA/Ro antibodies, three infants had first degree block, three had third degree block, and four had cutaneous neonatal lupus [5].

Anti-SSA/Ro and anti-SSB/La antibodies were present in $91 \%$ of mothers of infants with complete heart block, $73 \%$ of mothers of infants with transient cutaneous neonatal lupus, and $15 \%$ of mothers with lupus and related autoimmune diseases who gave birth to healthy infants $[6,7]$. 
The incidence of cardiac manifestations in neonatal lupus increases to about $17 \%$ in women with anti-SSA/Ro and/or anti-SSB/La antibodies who have had a previous child with congenital heart block [8], a previous child with cutaneous neonatal lupus without cardiac manifestations [9], and in women with high titers of anti-SSA/Ro and anti-SSB/La compared to low titers [10]. On the other hand, infants exposed to high titers of anti-SSB/La were more likely to have noncardiac manifestations of neonatal lupus [10].

\section{Pathogenesis}

During fetal life a physiologic process of cell apoptosis occurs resulting in translocation and expression of nuclear antigens and phospholipids on the cell surface displaying immunogenic surface blebs which are continuously cleared. However, if the balance between the rate of production and clearance of this apoptotic debris is impaired, resulting in an excess antigen expression, the immune system forms antibodies to these nuclear antigens and phospholipids. These antinuclear antibodies (ANAs) include anti-Sjögren's syndrome A (SSA/Ro), anti-Sjögren's syndrome B (SSB/La), ribonuclear protein (RNP), and antiphospholipid (APL) antibodies. Autoantibodies often are benign but can also induce inflammatory damage to tissues like blood vessels and organs, leading to clinical autoimmune diseases.

Maternal antibodies are of immunoglobulin G ( $\operatorname{IgG}$ ) nature antibodies which cross the placenta to the fetus in the second trimester reaching maternal concentrations by 30 weeks' gestation, and exceed maternal concentrations by term [11]. Maternal autoantibodies mediate fetal autoimmune disease through formation of antibody complexes with apoptotic antigens in the skin, liver, heart and newly forming bone which when phagocytosed and opsonized initiate proinflammatory process that results in immune-mediated damage to fetal tissues $[12,13]$.

Several studies have established the association between antibodies against the $60 \mathrm{kD}$ extractable nuclear antigens Ro (anti-SSA/Ro) and La (anti-SSB/La) and neonatal lupus. In addition to the traditional Ro antigen of $60 \mathrm{kD}$, another antigen of $52 \mathrm{kD}$ has been identified. Antibodies with specificity for the $52 \mathrm{kD}$ component of the SSA/Ro protein (Ro52) are more frequently found and are present at higher concentrations in the serum of children with congenital heart block and their mothers [14,15]. More specifically, maternal anti Ro-52 kD antibodies with primary specificity for a particular peptide fragment (amino acids 200 through 239, p200-239) are significantly associated with the development of CHB $[15,16]$. Although maternal anti Ro52-p200 antibody exposure was observed in equal frequency in both affected and unaffected offspring [17], higher levels of Ro52 p200 antibodies were observed in mothers of children with CHB compared to those with normal children [18]. Cutaneous NL was present in $16 \%$ of women with anti-SSA/Ro antibodies and was significantly more frequent in those with both anti-SSA/Ro and anti-SSB/La autoantibodies [3].

The pathogenesis of heart block results from binding of anti-SSA/Ro and/or anti-SSB/La antibodies to fetal cardiac tissue, leading to autoimmune injury of the atrioventricular (AV) node and its surrounding tissue $[19,20]$. Apoptosis induced translocation of SSA/Ro and SSB/La to the surface of fetal cardiomyocytes allows anti-SSA/Ro and anti-SSB/La antibodies to bind to the surface of the fetal cardiomyocytes [21]. Apoptotic cardiomyocytes are then phagocytosed by healthy fetal cardiomyocytes diverting these opsonized cardiomyocytes to uptake by macrophages [22], which release pro-inflammatory cytokines, initiating an inflammation-free physiologic remodelling of the human fetal heart and resulting in inflammation-induced tissue damage [23]. Tumor necrosis factor alpha and transforming growth factor beta may potentiate the inflammatory and fibrosis components respectively [24]. In addition to inducing tissue damage, anti-SSA/Ro and/or anti-SSB/La antibodies may inhibit calcium channel activation or the cardiac L-type calcium channels which are crucial to action potential propagation and conduction in the AV and SA nodes [25,26].

Maternal antibodies to other antigens like anti-U1 ribonuclear protein antibodies in the absence of anti-SSA/Ro or anti-SSB/La antibodies were found to cause classic rash of NL, but not congenital heart block $[27,28]$.

Genetic predisposition, particularly the HLA alleles DQB1 ${ }^{\star} 02$, $\mathrm{DRB} 1^{\star} 03$, and a polymorphism in the promoter region of the gene for tumor necrosis factor alpha may play a role in skin disease. The frequency of carriage of all three alleles in infants with characteristic lupus rash was twice that of infants with $\mathrm{CHB}$ or unaffected infants [29].

\section{Clinical Presentation}

Clinical manifestations and outcomes of different body systems involvement in neonatal lupus are summarized in (Table 1).

\section{Skin Manifestations}

Skin manifestation of NLS occurs in association with the $52-\mathrm{kD}$ SSA/Ro, 60-kD SSA/Ro, 48-kD SSB/La, and U1RNP autoantibodies. The rash typically appears during the first 3 postnatal months, persists for a mean of 4 months, and spontaneously resolves by 6 to 8 months of age parallel with fading of maternal autoantibodies in the infant's circulation. However, residual skin abnormalities occur in $10 \%$ to $25 \%$ of infants and include telangiectasias, dyspigmentation, pitting, scarring, and skin atrophy.

Neonatal lupus rash is characterized by round or elliptical erythematous, papulosquamous lesions with central clearing, annular erythema, and a fine scale. Blueberry muffin rashes have been also described in cases of neonatal lupus representing extramedullary dermal erythropoiesis secondary to severe intrauterine anemia mediated by maternal autoantibodies. The rash typically involves the face, scalp, neck, trunk, extremities, and intertriginous areas and is frequently induced or exacerbated by ultraviolet light (sunlight or phototherapy).

The histopathology of the erythematous-desquamative lesions shows vacuolar alterations at the dermoepidermal interface and adnexal structures [30]. Some patients present with urticaria-like lesions that have superficial and deep perivascular and periadnexal lymphocytic infiltrates.

\section{Cardiac Manifestations}

The main cardiac manifestations of NLS are injury to the conducting system, myocarditis and ventricular endocardial fibroelastosis through an antibody-mediated injury to fetal and neonatal cardiac conduction tissue, myocardium and endocardium respectively [16,31-33].

Injury to the conducting system presents mainly with congenital heart block (Figure 1) and to less extent with transient sinus bradycardia, QT interval prolongations, and Wolff-Parkinson-White syndrome [34,35]. Neonatal Lupus Syndrome accounts for $85 \%$ of all cases of congenital complete heart block [36]. The incidence of heart 


\begin{tabular}{|c|c|c|c|}
\hline System & Clinical manifestations & Treatment (Level of Evidence) & Outcome \\
\hline \multirow{8}{*}{ Skin } & 1.Transient lesions & \multirow{8}{*}{$\begin{array}{l}\text { - Conservative } \\
\text { - Avoid ultraviolet light exposure (III) } \\
\text { - Consider topical Corticosteroids (III) }\end{array}$} & \multirow{8}{*}{ Spontaneously resolve by $6-8$ months } \\
\hline & a.Erythematous, papulosquamous, desquamative rash & & \\
\hline & b.Blueberry muffin rash & & \\
\hline & 2.Permanent lesions & & \\
\hline & c.Telangiectasias & & \\
\hline & e.Skin pitting & & \\
\hline & f.Skin scarring & & \\
\hline & g.Skin atrophy & & \\
\hline \multirow{14}{*}{ Cardiac } & 2.Conductive system affection & \multirow{14}{*}{$\begin{array}{l}\text { - Conservative management with close } \\
\text { monitoring } \\
\text { - Corticosteroids for active carditis (III) } \\
\text { - Cardiac pacemaker for life-threatening } \\
\text { condition (Ila) } \\
\text { - Management of heart failure }\end{array}$} & \multirow{14}{*}{$\begin{array}{l}\text { - Mortality: } 19 \% \text { of infants with } \mathrm{CHB} \\
\text { - Cardiac pacemaker: } 65 \% \text { of survivors }\end{array}$} \\
\hline & a.Congenital Heart Block (CHB) & & \\
\hline & b. Transient sinus bradycardia & & \\
\hline & d.Wolff-Parkinson- White syndrome & & \\
\hline & 3.Inflammatory manifestations & & \\
\hline & a.Myocarditis & & \\
\hline & b.Endocardialfibroelastosis & & \\
\hline & 4.Structural defect & & \\
\hline & a.VSD & & \\
\hline & b.PDA & & \\
\hline & c.Patent foramen ovale & & \\
\hline & d.Pulmonary stenosis & & \\
\hline & e.Pulmonary valvular dysplasia & & \\
\hline & f.ASD & & \\
\hline \multirow{5}{*}{ Haematology } & 1.Anemia & \multirow{5}{*}{$\begin{array}{l}\text { - Conservative for mild cases } \\
\text { - IVIG ( } 1 \mathrm{~g} / \mathrm{kg} \text { for } 1 \text { to } 2 \text { days) for refracto- } \\
\text { ry anemia or thrombocytopenia (III) } \\
\text { - Corticosteroids ( } 1 \text { to } 2 \mathrm{mg} / \mathrm{kg} \text { for } 5 \text { days) } \\
\text { for refractory anemia or thrombocyto- } \\
\text { penia (III) } \\
\text { - Anticoagulants for thrombosis (III) } \\
\text { - Consult hematology }\end{array}$} & \multirow{5}{*}{$\begin{array}{l}\text { Resolve by 3-6 months with fading of maternal } \\
\text { antibodies }\end{array}$} \\
\hline & 3.Neutropenia & & \\
\hline & 4.Bone marrow failure & & \\
\hline & 5.Disseminated intravascular coagulation & & \\
\hline & 6.Hyper-coagulation andthrombosis & & \\
\hline \multirow{3}{*}{ Hepatobilary } & 1.Neonatal cholestasis & \multirow{9}{*}{$\begin{array}{l}\text { - Corticosteroids if severe or persistent } \\
\text { hepatitis (III) } \\
\text { - Immunosuppressive therapy (III) } \\
\text { - Immunosuppressive therapy (III) } \\
\text { - Endocrine consultation } \\
\text { - Hormonal replacement therapy when } \\
\text { indicated } \\
\text { - Genetics and orthopaedics consultation }\end{array}$} & \multirow{9}{*}{$\begin{array}{l}\text { Resolve by 3-6 months with fading of maternal } \\
\text { antibodies }\end{array}$} \\
\hline & 2.Neonatal hepatitis & & \\
\hline & 3.Liver cell failure & & \\
\hline \multirow{2}{*}{ Pulmonary } & 1.Pneumonitis & & \\
\hline & 2.Pulmonary capillaritis & & \\
\hline \multirow{2}{*}{ Renal } & 1.Glomerulonephritis & & \\
\hline & 2.Nephrotic syndrome & & \\
\hline Endocrine & 2.Adrenal insufficiency & & \\
\hline Musculoskeletal & Rhizomelicchondrodysplasiapunctata & & \\
\hline \multirow{7}{*}{ Neurologic } & 1.Seizures & \multirow{7}{*}{$\begin{array}{l}\text { - Obtain brain MRI for tome abnormalities } \\
\text { - Obtain electroencephalograph if seizure } \\
\text { is suspected } \\
\text { - Conservative management with close } \\
\text { monitoring }\end{array}$} & \multirow{7}{*}{$\begin{array}{l}\text { Some infants develop } \\
\text { 1. Learning disabilities } \\
\text { 2. ADHD } \\
\text { 3. Developmental delay } \\
\text { 4. Obsessive compulsive disorders }\end{array}$} \\
\hline & 2.Strabismus & & \\
\hline & 3.Opsoclonus & & \\
\hline & 4.Truncalhypotonia, & & \\
\hline & 5.Spastic paresis & & \\
\hline & 6.Myelopathies & & \\
\hline & 7.Intra-cerebral haemorrhages & & \\
\hline
\end{tabular}

Table 1: Common clinical manifestations and related outcomes of neonatal lupus.

Levels of evidence: la - Evidence from Meta-analysis of Randomized Controlled Trials, lb - Evidence from at least one Randomized Controlled Trial, Ila - Evidence from at least one well designed controlled trial which is not randomized, Ilb - Evidence from at least one well designed experimental trial, III - Evidence from case, correlation, and comparative studies, IV - Evidence from a panel of experts. 
block in infants born to mothers who have anti-Ro/SSA or anti-La/SSB antibodies is $1 \%$ to $2 \%$ in the first pregnancy and increases to $16 \%$ to $18 \%$ in subsequent pregnancies [37,38]. Injury to fetal and neonatal cardiac conduction tissue occurs as a consequence of a cascade of inflammatory events starts with cardiocyte apoptosis and progress through translocation of SSA/Ro and SSB/La antigens to the cardiocyte surface, binding of maternal autoantibodies, macrophage recruitment, secretion of profibrosing factors, and fibrosis of the cardiac conduction system [34,39]. Most cases of $\mathrm{CHB}$ are detected before 30 weeks' gestation, with a peak incidence between 20 and 24 weeks [36].

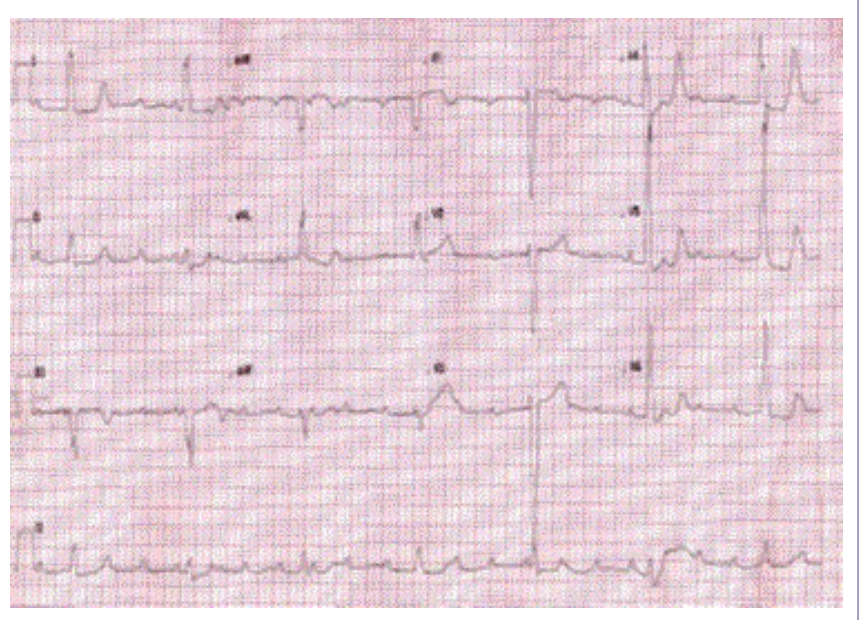

Figure 1: Congenital complete heart block in newborn with NLS.

Myocarditis and ventricular endocardial fibroelastosis occur with NLS as a result of inflammatory cell infiltrates and deposition of immunoglobulin, complement, and fibrin in the myocardium [40]. Myocarditis is often followed by the development of postnatal cardiomyopathy in approximately $10 \%$ of infants who have NLS leading to poor prognosis [32].

Neonatal lupus with CHB has been associated with endocardial fibroelastosis which may present early during fetal, during immediate postnatal life, or late as long as five years after the diagnosis of complete heart block $[32,41]$. Structural heart disease, particularly VSD, has been reported occasionally in association with NL and heart block $[42,43]$. Other congenital structural cardiac anomalies have been observed in association with NL include persistent patent ductus arteriosus, patent foramen ovale, pulmonary stenosis, pulmonary valvular dysplasia, fusion of chordae tendineae of the tricuspid valve, and ostium secundum type atrial septal defects $[42,44]$.

\section{Haematological Manifestations}

Haematological manifestations of NLS include anemia, neutropenia, thrombocytopenia, bone marrow failure, disseminated intravascular coagulation, and thrombosis. Cytopenias are the classic haematological presentation of neonatal lupus mainly due to immune suppression of the bone marrow by maternal autoantibodies and to less extent due to peripheral destruction of blood components. Maternal auto-antibodies SSA/Ro and SSB/La are associated with neonatal cytopenias and antiplatelet antibodies have been described in association with thrombocytopenia.

Anemia and thrombocytopenia are the most common hematologic manifestations, while neutropenia and aplastic anemia are rare. Hemolytic anemia is a rare manifestation of NLS. Immune thrombocytopenic purpura with microangiopathic hemolytic anemia and disseminated intravascular coagulation has been reported in an infant who had NLS [45].

Bone marrow aspiration is characterised by the presence of teardrop cells and basophilic stippling. Haematological abnormalities are typically worsened over the first days after birth, and resolve after disappearance of maternal autoantibodies.

Hyper-coagulation and thrombosis has been descried with NLS due to transplacentally acquired antiphospholipid (APL) antibodies, especially in the setting of sepsis, indwelling catheters, or other situations where vessel injury predisposes to thromboses [38].

\section{Hepatobiliary Manifestations}

Hepatic involvement occurs in $9 \%$ to $25 \%$ of infants who have NLS as an isolated disease or within a wider spectrum of the NLS manifestations [3]. The two most common presentations of NLS liver disease are neonatal cholestasis with or without elevated transaminases occurring in the first few weeks after birth and isolated mild elevated transaminases occurring at 2 to 3 months of age [46]. Severe perinatal hepatic dysfunction, often with the phenotype of neonatal iron storage disease, portends a poor prognosis [46]. Histopathology examination, in severe and persistent cases of liver dysfunction, typically shows mild bile duct obstruction, portal fibrosis, and occasional giant cell transformation similar to idiopathic neonatal giant cell hepatitis [47]. Most cases of neonatal lupus have spontaneous resolution of hepatic disease by 3 to 6 months after clearance of maternal autoantibodies, however deaths from hepatic failure have previously been reported.

\section{Pulmonary and Renal Manifestations}

Pulmonary and renal involvements are rare in infants with NLS and their presence may be suggestive of infantile primary SLE [48]. Pulmonary manifestations are commonly presented as cough, tachypnea, hypoxemia, and a chest radiograph of interstitial lung infiltrates. The pathogenesis for lung involvement in NLS includes necrotizing pulmonary capillaritis, pneumonitis, and alveolar hemorrhage [49]. The common presenting renal manifestations are hematuria, hypertension, and edema related to glomerulonephritis and congenital nephrotic syndrome [50]. However, nephritis and nephritic presentations suggest the diagnosis of infantile lupus and not NLS. This is possibly related to absence of antibody deposition in the fetal kidney due to absence of renal antigens during fetal life [51].

\section{Endocrine Manifestations}

Thyroid and adrenal dysfunctions are the most common endocrine sequelae of neonatal lupus. Since thyroid disease represents a prevalence of $14 \%$ to $20 \%$ in women who have SLE and Sjogren syndrome [52], assessment of sick infants who have NLS should include evaluation for thyroid dysfunction and maternally derived blocking and stimulating thyroid antibodies. Women who have hypothyroidism and SSA/Ro antibodies have a nine fold increased risk for delivering a child who has $\mathrm{CHB}$ compared with women who have only SSA/Ro antibodies [53]. Transplacental passage of thyroid blocking or stimulating antibodies is associated with hypo or hyper thyroid disease of neonates [54].

Bilateral massive adrenal hemorrhage and adrenal insufficiency has been previously reported with transplacental acquired antiphospholipid antibodies [55]. 


\section{Musculoskeletal Manifestations}

Rhizomelic chondrodysplasia punctata has been reported in infants born to mothers who had SLE antibodies, none of them had cataracts or defects in peroxisomal metabolism which is typical of the genetic forms of chondrodysplasia punctata [56]. They typically present with midfacial hypoplasia, shortening of the proximal limbs, and punctuate calcifications of the epiphyses in any of the humerus, femur, tibia, tarsal bones, heels, phalanges, and vertebral spine. Rhizomelic chondrodysplasia punctata may be an isolated presentation or occur in association with NLS rash and CNS manifestations.

Similar to other NLS manifestation rhizomelic chondrodysplasia punctata occurs as a result of IgG-apoptotic cell complexes presented in the zones of newly forming fetal bones initiating an immune complex-mediated inflammation at growth plates [12].

\section{Neurologic Manifestations}

Trans-placental passage of maternal auto-antibodies results in lenticulostriate vasculopathy and subsequent brain abnormalities as cerebral dysmaturation, cortical dysgenesis, ventriculomegaly, and dysgenesis of structures supplied by the lenticulostriate vasculature in infants with NLS [57-59].

Although most infants who have NLS are asymptomatic at birth, seizures, strabismus, opsoclonus, truncal hypotonia, spastic paresis, myelopathies, cerebral haemorrhages, static encephalopathies, and developmental delay have been observed in infancy. Children born to women who have SLE and concurrent APL antibodies showed increased rate of learning disabilities [60]. Infants who have idiopathic lenticulostriate vasculopathies were more likely to have muscle tone abnormalities at 6 months of age and may have an increased risk of developing attention deficits, hyperactivity, obsession/compulsion, and tic disorders $[61,62]$.

Radiologic evaluations have shown evidences of white matter disease, cerebral edema, hypomyelination, echogenic lenticulostriate vessels, basal ganglia calcifications, gangliothalamic vasculopathy, subependymal cysts, haemorrhages, and ventriculomegaly [57,63-65]. Less common radiological findings in infants who had NLS include thalamostriatal malformations, absent septum pellucidum, prominent cavum septum pellucidum, optic chiasm and optic nerve hypoplasia, and cortical dysgenesis. A statistically significant association has been observed between neonatal intraventricular hemorrhage and lenticulostriate vasculopathy in infants with NLS [66]. The prevalence of hydrocephalus and macrocephaly also is increased in infants born to mothers who have anti-SSA/Ro antibodies [63].

Although the relation between maternal autoantibodies and neonatal neurological diseases is not yet known to be true or confounded, clinical and experimental evidence support a true association. The known connection between autoantibodies, in the setting of SLE, Sjögren syndrome, and APL syndrome, with adult human CNS diseases like CNS vasculitis, white matter lesions, chorea, seizures, and cognitive dysfunction supports the association between neonatal CNS injury and maternal autoantibodies. Additionally, animal studies show that APL, anti-SSA/Ro, and antidsDNA antibodies mediate neurologic dysfunction, potentiate seizures, and lead to excitotoxic injury to the animal brain [67-73].

\section{Diagnosis}

The diagnosis of NL is made when a fetus or newborn of a mother with anti-SSA/Ro and/or anti-SSB/La, or possibly anti-RNP, antibodies develops heart block and/or the typical rash or hepatic or hematologic manifestations in the absence of another explanation. Skin manifestation of NLS should be differentiated from various erythematous rashes seen in the neonatal period particularly erythema marginatum, tinea seborrheic dermatitis, ichthyosiform genodermatosis, erythema annulare centrifugum, familial annular erythema, erythema multiforme, infantile epidermodysplastic erythema, annular erythema of infancy, and erythema gyratum atrophicans [74]. However, skin rashes not related to NLS are not associated with maternal anti-SSA/Ro, anti-SSB/La antibodies or with congenital heart block. Congenital heart block related to NLS should be differentiated from other causes of $\mathrm{CHB}$ such as myocarditis, various structural cardiac defects, congenitally corrected transposition of the great arteries, and atrioventricular discordance [41]. Early presentation during fetal life and additional structural cardiac abnormalities such as VSD and endocardial fibroelastosis along with presence of antibodies to SSA/SSB favours the diagnosis of NLS.

\section{Prenatal screening}

Prenatal screening for anti-SSA/Ro and anti-SSB/La antibodies, prior to conception or as early in pregnancy as possible, is warranted for women who are known to have lupus, Sjogren s yndrome, an undifferentiated autoimmune disease, or NL in a previous pregnancy. Neonatal lupus in an offspring can be the first sign that the mother has anti-SSA/Ro and anti-SSB/La antibodies.

Fetal congenital heart block occurs mostly during the period from 18 to 24 weeks gestation, less likely during the 26th through the 30th week, and rarely after 30 weeks of pregnancy. Normal sinus rhythm can progress to complete block in seven days during the initial high-risk period.

Complete heart block results in fetal bradycardia which can be detected by routine fetal auscultation, ultrasonography, or pulsed Doppler echocardiography [75,76]. Women who test positive for SSA/Ro and SSB/La autoantibodies should have a more intensive assessment for fetal heart block with frequent fetal echocardiographic testing during pregnancy. Although there are no formal guidelines for the type or the frequency of testing, performing weekly pulsed Doppler fetal echocardiography from the 18th through the 26th week of pregnancy and then every other week until 32 weeks has been strongly considered. Additional diagnostic modalities include fetal magnetocardiography and electrocardiography $[77,78]$.

\section{Postnatal diagnosis}

Newborns with heart block in absence of causal structural abnormalities should be testing for maternal anti-SSA/Ro antibodies because these antibodies account for 80 to $95 \%$ of reported cases of CHB in the fetus and neonate $[41,79]$.

Infants up to eight months of age with an annular or polycyclic rash and/or any degree of heart block should be tested for anti-SSA/Ro and anti-SSB/La antibodies.

Infants diagnosed with NL who has compatible clinical manifestations and detectable autoantibodies with no electrocardiographic evidence of heart block of any degree at birth, is at very low risk of subsequently developing conducting system disease however they should be followed for later development of cardiomyopathy. 


\section{Management}

\section{Skin disease}

Treatment of skin manifestation is typically conservative with avoidance of sun or ultraviolet light exposure to prevent or minimize the rash and residual skin abnormalities. Topical corticosteroids have been previously evaluated, but the efficacy has not been established.

\section{Cardiac diseases}

The clinical relevance of first degree heart block is unclear as progression from first degree block to more advanced heart block in untreated fetuses has not been documented. Second degree heart block may be reversible and may progress to complete heart block despite therapy $[80,81]$. Complete heart block is irreversible even with glucocorticoid therapy $[76,80]$.

Prenatal treatment: Flourinated corticosteroids, as dexamethasone and betamthasone, and sympathomimetics have been used in mothers of affected fetuses to prevent in utero effusions, hydrops fetalis, and other complications of advanced heart block $[80,82,83]$, however the efficacy and safety of antenatal steroid therapy has been questioned. Previous reports have shown that fetuses with second degree heart block treated with dexamethasone or betamethasone reverted to first degree block by birth, while those who were not treated progressed to complete heart block [80]. In a multicenter study of antenatal dexamethasone therapy, $100 \%$ of fetuses with third degree block did not respond to therapy, $50 \%$ of infants with second degree block remained in second degree block, $30 \%$ reverted to normal sinus rhythm, and $20 \%$ progressed to third degree heart block, while $100 \%$ of fetuses with first degree block converted to normal sinus rhythm within one week [84]. In another multicenter prospective study, fetuses with first degree heart block, diagnosed by tissue velocity-based fetal kinetocardiogram, treated with antenatal dexamethasone had normalization of AV conduction in all affected fetuses within two weeks [85]. In a retrospective series of 37 patients with complete heart block, the one-year survival rate in the 21 patients treated with dexamethasone was $90 \%$, compared with a survival rate of $46 \%$ in the 16 untreated patients [82].

Fluorinated glucocorticoids are also considered for signs of cardiomyopathy. However, the effectiveness of these agents in the treatment of endocardial fibroelastosis is unknown [41]. In a retrospective study for the use of glucocorticoids and IVIG (both in utero and after birth), a potential survival benefit was observed in cases with cardiomyopathy/endocardial fibroelastosis based upon comparison to historical control data [86].

Plasmapheresis and intrauterine placement of a fetal pacemaker also have been attempted $[87,88]$. Intrapartum IVIG $(400 \mathrm{mg} / \mathrm{kg}$ given every three weeks from weeks 12 to 24) has also been used to prevent and treat $\mathrm{CHB}$ with limited success, but the safety profile maybe better than that of corticosteroids $[89,90]$.

Hydroxychloroquine (400 mg orally once a day) inhibits ligation of endosomal Toll-like receptors. It is often used during pregnancies complicated by lupus and considered of minimal risk to the fetus and mother. It should be initiated between 6 and 10 weeks gestation in women who are not already on the medication. In a case-control study of mothers with SLE treated with hydroxychloroquine, the overall risk of cardiac lupus was decreased [91]. A subsequent retrospective study based upon data from neonatal lupus registries in the United States, France, and the United Kingdom supports the efficacy of hydroxychloroquine in reducing the recurrence rate of cardiac-NL [92].

Accordingly, prenatal treatment with fluorinated glucocorticoids (oral dexamethasone $4 \mathrm{mg}$ per day, or betamethasone $3 \mathrm{mg}$ per day) is suggested for mothers of fetuses with second degree heart block, beginning as soon after detection and continuing through the end of pregnancy depending upon the response. Glucocorticoid therapy should be discontinued after one week of detection if heart block progresses to third degree block with no other signs of myocarditis. Most patients with third degree block will require cardiac pacing. Treatment of third degree block with glucocorticoids is generally not advised, unless there are other factors as suspected myocarditis and cardiomyopathy, although to date this has not been well evidenced $[82,93]$. Treatment of isolated first degree block is controversial, because of the risks of therapy, the evidence that first degree block can revert to normal sinus rhythm without therapy, and the absence of consistent evidence that untreated first degree block can progress to more advanced block [85,94]. Preemptive treatment with hydroxychloroquine in pregnant women who have previously given birth to a child with cardiac manifestations of neonatal lupus and who have anti-SSA/Ro antibodies has been shown to be promising.

Postnatal treatment: After delivery, infant electrocardiography should be obtained. When bradyarrhythmias or other arrhythmias are detected perinatally, infants should be monitored closely for progression of conduction abnormalities and cardiomyopathies. Treatment with sympathomimetic agents such as salbutamol and isoprenaline was proved, through case reports, to be effective prenatally in fetuses with congenital heart block [95] but not in postnatal management [96]. Post natal treatment with IVIG or glucocorticoids was found to be ineffective in neonates with CHB [97].

Infants born with congenital heart block may be indicated for permanent cardiac pacemaker insertion. Indications of cardiac pacing in cases of congenital heart block are summarized in (Table 2) $[98,99]$.

\begin{tabular}{|c|c|}
\hline Class & Indication \\
\hline \multirow{8}{*}{$\begin{array}{l}\text { Class I (Pacing is } \\
\text { indicated) }\end{array}$} & Congenital complete AV block with \\
\hline & a.Ventricular rate less than 50 beats per minute. \\
\hline & b.Wide QRS escape rhythm. \\
\hline & c.Prolonged QTc interval. \\
\hline & d.Complex ventricular ectopy. \\
\hline & e. Ventricular dysfunction. \\
\hline & $\begin{array}{l}\text { f. Ventricular pause }>3 \text { folds the cycle length of the underly- } \\
\text { ing rhythm }\end{array}$ \\
\hline & $\begin{array}{l}\text { g. Associated congenital heart disease and a ventricular rate } \\
\text { less than } 70 \text { beats per minute. }\end{array}$ \\
\hline \multirow[t]{4}{*}{$\begin{array}{l}\text { Class lla (Pacing is } \\
\text { reasonable) }\end{array}$} & $\begin{array}{l}\text { Congenital complete A-V block beyond the first year of life } \\
\text { with }\end{array}$ \\
\hline & a.Average heart rate less than 50 beats per minute. \\
\hline & $\begin{array}{l}\text { b. Abrupt pauses in ventricular rate of } 2 \text { or } 3 \text { times the basic } \\
\text { cycle length. }\end{array}$ \\
\hline & c. Associated symptoms due to chronotropic incompetence. \\
\hline $\begin{array}{l}\text { Class Ilb (Pacing is } \\
\text { considered) }\end{array}$ & $\begin{array}{l}\text { Congenital complete } \mathrm{A}-\mathrm{V} \text { block in asymptomatic children } \\
\text { with an acceptable rate, narrow QRS complex, and normal } \\
\text { ventricular function. }\end{array}$ \\
\hline $\begin{array}{l}\text { Class III (Pacing is } \\
\text { not indicated) }\end{array}$ & Asymptomatic type I (Wenckebach) second-degree AV block. \\
\hline
\end{tabular}

Table 2: Indication of cardiac pacemaker in infants with congenital heart block [98-100]. 
Pacing devices are divided into either single (conventional right ventricular) or dual (combined right and left ventricular) pace makers. The use of dual pace maker in infants and children was associated with less frequent left ventricular modeling, dilatation, and asymmetrical hypertrophy [101]. Conventional right ventricular pacemaker was found to be associated with significant increase in choronotropic insufficiency, cardiomyopathy, and acute heart failure particularly in infants of mothers with lupus [102,103].

\section{Haematological diseases}

Anaemia and thrombocytopenia are usually self-resolving and most infants do not need treatment and have spontaneous resolution of hematologic abnormalities with disappearance of maternal antibodies. Although irradiated blood products transfusion is indicated to control bleeding or to treat symptomatic anemia, they do not result in sustained counts when autoantibodies are present. In cases of fetal thrombocytopenia, postnatal management typically involves observation when platelet counts are greater than $20 \times 10^{3} /$ $\mathrm{mcL}\left(20 \times 10^{9} / \mathrm{L}\right)$ and there are no signs of bleeding.

Intravenous immunoglobulins (IVIG) at a dose of $1 \mathrm{~g} / \mathrm{kg} / \mathrm{day}$ for 1 or 2 days and corticosteroids at a dose of 1 to $2 \mathrm{mg} / \mathrm{kg} / \mathrm{day}$ for 5 days are instituted in cases of persistent, severe hematologic manifestations.

\section{Hepatobiliary diseases}

Corticosteroids should be initiated for severe or persistent moderate elevated transaminases at a dose of 1 to $2 \mathrm{mg} / \mathrm{kg}$ for 5 days or until an adequate response is achieved, followed by a slow wean. Transaminases should be monitored weekly during the corticosteroid wean, and worsening level should prompt escalation of corticosteroids therapy.

\section{Pulmonary and Renal}

The available evidence for management of pulmonary and renal manifestations is very restricted to few case reports. Success has been reported with corticosteroids and immunosuppressive therapy [49].

\section{Other Systems}

Musculoskeletal, endocrinal, and neurological diseases are managed according to the presenting manifestations. A multidisciplinary approach with involvement of other specialities is more beneficial for affected infants.

\section{Prognosis}

The prognosis of neonatal lupus depends mainly on the presence or absence of cardiac involvement. The rash of neonatal lupus generally does not cause scarring and disappears within six to eight months. Although cardiac involvement is rare in patients who had no evidence of heart block or who had noncardiac manifestations of neonatal lupus at birth, infants with noncardiac manifestations of NL should at least have an ECG, and possibly an echocardiogram, since first degree block is clinically silent and can progress postnatally.

In cases with heart block, mortality varies with the time of presentation representing $43 \%$ when diagnosed in utero by fetal echocardiography [41]. In neonates with congenital NLS, complete $\mathrm{CHB}$ is associated with significant morbidity and mortality representing $20 \%$ cumulative probability of death at 3 years, and $65 \%$ of survivors require pacemakers [36]. In a prospective observational study of infants and children with isolated congenital heart block, 67\% were diagnosed before one year of age [104]. In the same study, authors noticed that $46 \%$ of infants with isolated congenital heart block secondary to maternal lupus required pacemaker in the first 24 months of life [104].

Data from Research Registry for Neonatal Lupus revealed an overall mortality of infants with congenital complete heart block, born to mothers with anti-SSA/Ro or anti-SSB/La antibodies, of 19\%; $5 \%$ occurred in utero, $9 \%$ within the first three months of birth, $5 \%$ between the age of three months and three years, no deaths older than the age of three [42]. Of survivors, $63 \%$ ultimately required a pacemaker [42].

Previously reported fetal risk factors associated with increased mortality include early diagnosis (before 20 weeks gestational age), lower ventricular rate (less than 50 beats per minute), echocardiographic evidence of hydrops, echocardiographic evidence of endocardial fibroelastosis, and impaired left ventricular function at diagnosis [105,106].

Asymptomatic infants with complete heart block remain well until later childhood, adolescence, or adulthood. However, exercise limitation and even death are possible in the absence of pacing.

Children who have had NL may be at increased risk of developing an autoimmune and/or rheumatic disease including pauciarticular and polyarticular onset juvenile idiopathic arthritis, psoriasis, thyroid disease, iritis, type 1 diabetes mellitus, and nephrotic syndrome [107]. None of the children with neonatal disease, nor any of their unaffected siblings, developed systemic lupus erythematosus during at least eight years of follow-up [107].

\section{Summary}

Neonatal lupus is a multisystem disease which affects mainly the cardiac, dermatologic, and hepatobiliary systems. It occurs in infants born to mothers with rheumatic conditions including, but not restricted to, systemic lupus erythematosus. Most clinical manifestations of NLS resolve spontaneously with vanishing of maternal auto-antibodies from the neonatal circulation except congenital complete heart block. Prenatal diagnosis and management are cornerstones in the care of infants with neonatal lupus to prevent permanent damage to the conducting system of the heart and later development of complete heart block. Congenital complete heart block is a poor prognostic marker in infants with neonatal lupus syndrome. Cardiac pacemaker, preferably the dual chamber pacemaker, is frequently indicated in infants with congenital complete heart block related to neonatal lupus.

\section{Competing Interests}

The author declares no significant competing financial, professional or personal interests that might have influenced the performance or presentation of the work described in this manuscript.

\section{References}

1. Chakravarty EF1, Colón I, Langen ES, Nix DA, El-Sayed YY, et al. (2005) Factors that predict prematurity and preeclampsia in pregnancies that are complicated by systemic lupus erythematosus. Am J Obstet Gynecol 192: 1897-1904.

2. Brucato A1, Frassi M, Franceschini F, Cimaz R, Faden D, et al. (2001) Risk of congenital complete heart block in newborns of mothers with anti-Ro/SSA antibodies detected by counterimmunoelectrophoresis: a prospective study of 100 women.Arthritis Rheum 44: 1832-1835. 
3. Cimaz R1, Spence DL, Hornberger L, Silverman ED (2003) Incidence and spectrum of neonatal lupus erythematosus: a prospective study of infants born to mothers with anti-Ro autoantibodies.J Pediatr 142: 678-683.

4. Costedoat-Chalumeau N1, Amoura Z, Lupoglazoff JM, Huong DL, Denjoy I, et al. (2004) Outcome of pregnancies in patients with anti-SSA/Ro antibodies: a study of 165 pregnancies, with special focus on electrocardiographic variations in the children and comparison with a control group.Arthritis Rheum 50: 3187-3194.

5. Friedman DM, Kim MY, Copel JA, Davis C, Phoon CK, et al. (2008) Utility of cardiac monitoring in fetuses at risk for congenital heart block: the PR Interval and Dexamethasone Evaluation (PRIDE) prospective study.Circulation 117 485-493.

6. Buyon JP, Kim MY, Copel JA, Friedman DM (2001) Anti-Ro/SSA antibodies and congenital heart block: necessary but not sufficient.Arthritis Rheum 44: 1723-1727.

7. Buyon JP1, Winchester RJ, Slade SG, Arnett F, Copel J, et al. (1993) Identification of mothers at risk for congenital heart block and other neonatal lupus syndromes in their children. Comparison of enzyme-linked immunosorbent assay and immunoblot for measurement of anti-SS-A/Ro and anti-SS-B/La antibodies.Arthritis Rheum 36: 1263-1273.

8. Llanos C1, Izmirly PM, Katholi M, Clancy RM, Friedman DM, et al. (2009) Recurrence rates of cardiac manifestations associated with neonatal lupus and maternal/fetal risk factors.Arthritis Rheum 60: 3091-3097.

9. Izmirly PM1, Llanos C, Lee LA, Askanase A, Kim MY, et al. (2010) Cutaneous manifestations of neonatal lupus and risk of subsequent congenital heart block.Arthritis Rheum 62: 1153-1157.

10. Jaeggi E1, Laskin C, Hamilton R, Kingdom J, Silverman E (2010) The importance of the level of maternal anti-Ro/SSA antibodies as a prognostic marker of the development of cardiac neonatal lupus erythematosus a prospective study of 186 antibody-exposed fetuses and infants.J Am Coll Cardiol 55: 2778-2784.

11. Malek A1, Sager R, Kuhn P, Nicolaides KH, Schneider H (1996) Evolution of maternofetal transport of immunoglobulins during human pregnancy.Am J Reprod Immunol 36: 248-255.

12. Tran HB1, Macardle PJ, Hiscock J, Cavill D, Bradley J, et al. (2002) Anti-La/ SSB antibodies transported across the placenta bind apoptotic cells in fetal organs targeted in neonatal lupus.Arthritis Rheum 46: 1572-1579.

13. Clancy RM1, Buyon JP (2004) More to death than dying: apoptosis in the pathogenesis of SSA/Ro-SSB/La-associated congenital heart block.Rheum Dis Clin North Am 30: 589-602, $x$

14. Silverman ED1, Buyon J, Laxer RM, Hamilton R, Bini P, et al. (1995) Autoantibody response to the Ro/La particle may predict outcome in neonatal lupus erythematosus. Clin Exp Immunol 100: 499-505.

15. Salomonsson S1, Dörner T, Theander E, Bremme K, Larsson P, et al. (2002) A serologic marker for fetal risk of congenital heart block.Arthritis Rheum 46 : 1233-1241.

16. Salomonsson S1, Sonesson SE, Ottosson L, Muhallab S, Olsson T, et al. (2005) Ro/SSA autoantibodies directly bind cardiomyocytes, disturb calcium homeostasis, and mediate congenital heart block.J Exp Med 201: 11-17.

17. Clancy RM1, Buyon JP, Ikeda K, Nozawa K, Argyle DA, et al. (2005) Maternal antibody responses to the 52-kd SSA/RO p200 peptide and the development of fetal conduction defects. Arthritis Rheum 52: 3079-3086.

18. Strandberg L1, Winqvist O, Sonesson SE, Mohseni S, Salomonsson S, et al. (2008) Antibodies to amino acid 200-239 (p200) of Ro52 as serological markers for the risk of developing congenital heart block.Clin Exp Immunol 154: $30-37$.

19. Ho SY, Esscher E, Anderson RH, Michaëlsson M (1986) Anatomy of congenital complete heart block and relation to maternal anti-Ro antibodies.Am J Cardiol 58: 291-294.
20. Alexander E1, Buyon JP, Provost TT, Guarnieri T (1992) Anti-Ro/SS-A antibodies in the pathophysiology of congenital heart block in neonatal lupus syndrome, an experimental model. In vitro electrophysiologic and immunocytochemical studies.Arthritis Rheum 35: 176-189.

21. Neufing PJ1, Clancy RM, Jackson MW, Tran HB, Buyon JP, et al. (2005) Exposure and binding of selected immunodominant La/SSB epitopes on human apoptotic cells.Arthritis Rheum 52: 3934-3942.

22. Clancy RM1, Neufing PJ, Zheng P, O'Mahony M, Nimmerjahn F, et al. (2006) Impaired clearance of apoptotic cardiocytes is linked to anti-SSA/Ro and -SSB/La antibodies in the pathogenesis of congenital heart block.J Clin Invest 116: $2413-2422$

23. Miranda-Carús ME1, Askanase AD, Clancy RM, Di Donato F, Chou TM, et al. (2000) Anti-SSA/Ro and anti-SSB/La autoantibodies bind the surface of apoptotic fetal cardiocytes and promote secretion of TNF-alpha by macrophages.J Immunol 165: 5345-5351.

24. Clancy RM1, Askanase AD, Kapur RP, Chiopelas E, Azar N, et al. (2002) Transdifferentiation of cardiac fibroblasts, a fetal factor in anti-SSA/Ro-SSB/ La antibody-mediated congenital heart block.J Immunol 169: 2156-2163.

25. Xiao GQ1, Hu K, Boutjdir M (2001) Direct inhibition of expressed cardiac I- and t-type calcium channels by igg from mothers whose children have congenital heart block.Circulation 103: 1599-1604.

26. Karnabi E, Qu Y, Mancarella S, Boutjdir M (2011) Rescue and worsening of congenital heart block-associated electrocardiographic abnormalities in two transgenic mice. J Cardiovasc Electrophysiol 22:922-30.

27. Provost TT, Watson R, Gammon WR, Radowsky M, Harley JB, et al. (1987) The neonatal lupus syndrome associated with U1RNP (nRNP) antibodies.N Engl J Med 316: 1135-1138.

28. Sheth AP1, Esterly NB, Ratoosh SL, Smith JP, Hebert AA, et al. (1995) U1RNP positive neonatal lupus erythematosus: association with anti-La antibodies?Br J Dermatol 132: 520-526.

29. Clancy RM1, Backer CB, Yin X, Chang MW, Cohen SR, et al. (2004) Genetic association of cutaneous neonatal lupus with HLA class II and tumor necrosis factor alpha: implications for pathogenesis.Arthritis Rheum 50: 2598-2603.

30. Peñate $Y 1$, Guillermo N, Rodríguez J, Hernández-Machín B, Montenegro T, et al. (2009) Histopathologic characteristics of neonatal cutaneous lupus erythematosus: description of five cases and literature review.J Cutan Pathol 36: $660-667$

31. Friedman DM1, Rupel A, Buyon JP (2007) Epidemiology, etiology, detection, and treatment of autoantibody-associated congenital heart block in neonatal lupus.Curr Rheumatol Rep 9: 101-108.

32. Nield LE1, Silverman ED, Taylor GP, Smallhorn JF, Mullen JB, et al. (2002) Maternal anti-Ro and anti-La antibody-associated endocardial fibroelastosis. Circulation 105: 843-848.

33. Gladman G1, Silverman ED, Yuk-Law, Luy L, Boutin C, et al. (2002) Fetal echocardiographic screening of pregnancies of mothers with anti-Ro and/or anti-La antibodies.Am J Perinatol 19: 73-80.

34. Askanase AD1, Friedman DM, Copel J, Dische MR, Dubin A, et al. (2002) Spectrum and progression of conduction abnormalities in infants born to mothers with anti-SSA/Ro-SSB/La antibodies.Lupus 11: 145-151.

35. Chunharas A1, Nuntnarumit $P$, Hongeng S, Chaunsumrit A (2002) Neonatal lupus erythematosus: clinical manifestations and management.J Med Assoc Thai 85 Suppl 4: S1302-1308.

36. Buyon JP1, Clancy RM (2005) Neonatal lupus: basic research and clinical perspectives. Rheum Dis Clin North Am 31: 299-313, vii.

37. Brucato A1, Doria A, Frassi M, Castellino G, Franceschini F, et al. (2002) Pregnancy outcome in 100 women with autoimmune diseases and anti-Ro/ SSA antibodies: a prospective controlled study.Lupus 11: 716-721.

38. Cimaz R1, Descloux E (2006) Pediatric antiphospholipid syndrome.Rheum Dis Clin North Am 32: 553-573. 
39. Moak JP1, Barron KS, Hougen TJ, Wiles HB, Balaji S, et al. (2001) Congenital heart block: development of late-onset cardiomyopathy, a previously underappreciated sequela.J Am Coll Cardiol 37: 238-242.

40. Tseng CE1, Buyon JP (1997) Neonatal lupus syndromes.Rheum Dis Clin North Am 23: 31-54.

41. Jaeggi ET1, Hamilton RM, Silverman ED, Zamora SA, Hornberger LK (2002) Outcome of children with fetal, neonatal or childhood diagnosis of isolated congenital atrioventricular block. A single institution's experience of 30 years.J Am Coll Cardiol 39: 130-137.

42. Buyon JP, Hiebert R, Copel J, Craft J, Friedman D, et al. (1998) Autoimmune-associated congenital heart block: demographics, mortality, morbidity and recurrence rates obtained from a national neonatal lupus registry. J Am Coll Cardiol 31:1658-1666.

43. Falcini F1, De Simone L, Donzelli G, Cerinic MM (1998) Congenital conduction defects in children born to asymptomatic mothers with anti-SSA/SSB antibodies: report of two cases.Ann Ital Med Int 13: 169-172.

44. Fu LS1, Hwang B, Lee BH (1992) Newborns of Chinese mother with Systemic Lupus Erythematosus (SLE).Zhonghua Min Guo Xiao Er Ke Yi Xue Hui Za Zhi 33: 341-349.

45. Hariharan D1, Manno CS, Seri I (2000) Neonatal lupus erythematosus with microvascular hemolysis.J Pediatr Hematol Oncol 22: 351-354.

46. Lee LA1, Sokol RJ, Buyon JP (2002) Hepatobiliary disease in neonatal lupus: prevalence and clinical characteristics in cases enrolled in a national registry. Pediatrics 109: E11.

47. Laxer RM1, Roberts EA, Gross KR, Britton JR, Cutz E, et al. (1990) Liver disease in neonatal lupus erythematosus.J Pediatr 116: 238-242.

48. Massengill SF1, Richard GA, Donnelly WH (1994) Infantile systemic lupus erythematosus with onset simulating congenital nephrotic syndrome.J Pediatr 124: 27-31.

49. Morton RL1, Moore C, Coventry S, Langston C, Schikler K, et al. (2004) Pulmonary capillaritis and hemorrhage in neonatal lupus erythematosus (NLE).J Clin Rheumatol 10: 130-133.

50. Lam C1, Imundo L, Hirsch D, Yu Z, D’Agati V (1999) Glomerulonephritis in a neonate with atypical congenital lupus and toxoplasmosis.Pediatr Nephrol 13: $850-853$.

51. Westenend PJ (1995) Congenital nephrotic syndrome in neonatal lupus syndrome.J Pediatr 126: 851.

52. Szyper-Kravitz M1, Marai I, Shoenfeld Y (2005) Coexistence of thyroid autoimmunity with other autoimmune diseases: friend or foe? Additional aspects on the mosaic of autoimmunity.Autoimmunity 38: 247-255.

53. Spence D1, Hornberger L, Hamilton R, Silverman ED (2006) Increased risk of complete congenital heart block in infants born to women with hypothyroidism and anti-Ro and/or anti-La antibodies.J Rheumatol 33: 167-170.

54. Dallas JS (2003) Autoimmune thyroid disease and pregnancy: relevance for the child.Autoimmunity 36: 339-350.

55. Teyssier G1, Gautheron V, Absi L, Galambrun C, Ravni C, et al. (1995) [Anticardiolipin antibodies, cerebral ischemia and adrenal hemorrhage in a newborn infant].Arch Pediatr 2: 1086-1088.

56. Shanske AL1, Bernstein L, Herzog R (2007) Chondrodysplasia punctata and maternal autoimmune disease: a new case and review of the literature.Pediatrics 120: e436-441.

57. Prendiville JS1, Cabral DA, Poskitt KJ, Au S, Sargent MA (2003) Central nervous system involvement in neonatal lupus erythematosus.Pediatr Dermato 20: $60-67$.

58. Zuppa AA1, Gallini F, De Luca D, Luciano R, Frezza S, et al. (2004) Cerebra ultrasound findings in neonatal lupus syndrome.Biol Neonate 86: 230-234
59. Inoue K1, Fukushige J, Ohno T, Igarashi H, Hara T (2002) Central nervous system vasculopathy associated with neonatal lupus.Pediatr Neurol 26: 6870

60. Neri F1, Chimini L, Bonomi F, Filippini E, Motta M, et al. (2004) Neuropsychological development of children born to patients with systemic lupus erythematosus.Lupus 13: 805-811.

61. Wang HS, Kuo MF (2003) Sonographic lenticulostriate vasculopathy in infancy with tic and other neuropsychiatric disorders developed after 7 to 9 years of follow-up. Brain Dev25:S43-7.

62. Hemachandra AH1, Oravec D, Collin M, Tafari N, Mhanna MJ (2003) Early and late postnatal identification of isolated lenticulostriate vasculopathy in preterm infants: associated findings.J Perinatol 23: 20-23.

63. Boros CA1, Spence D, Blaser S, Silverman ED (2007) Hydrocephalus and macrocephaly: new manifestations of neonatal lupus erythematosus.Arthritis Rheum 57: 261-266.

64. Cabañas F1, Pellicer A, Valverde E, Morales C, Quero J (1996) Central nervous system vasculopathy in neonatal lupus erythematosus.Pediatr Neurol 15: $124-126$.

65. Nakayama-Furukawa F, Takigawa M, Iwatsuki K, Sato N, Sato H (1994) Hydrocephalus in two female siblings with neonatal lupus erythematosus.Arch Dermatol 130: 1210-1212.

66. Mittendorf R, Covert R, Pryde PG, Lee KS, Ben-Ami T, et al. (2004) Association between Lenticulostriate Vasculopathy (LSV) and neonatal Intraventricular Hemorrhage (IVH). J Perinatol 24:700-5.

67. Chapman J1, Shoenfeld Y (2002) Neurological and neuroendocrine-cytokine inter-relationship in the antiphospholipid syndrome.Ann N Y Acad Sci 966: 415-424.

68. Shoenfeld Y, Nahum A, Korczyn AD, Dano M, Rabinowitz R, et al. (2003) Neuronal-binding antibodies from patients with antiphospholipid syndrome induce cognitive deficits following intrathecal passive transfer. Lupus 12:436442.

69. Katzav A1, Chapman J, Shoenfeld Y (2003) CNS dysfunction in the antiphospholipid syndrome.Lupus 12: 903-907.

70. Kent M1, Alvarez F, Vogt E, Fyffe R, Ng AK, et al. (1997) Monoclonal antiphosphatidylserine antibodies react directly with feline and murine central nervous system.J Rheumatol 24: 1725-1733.

71. Izmirly PM1, Rivera TL, Buyon JP (2007) Neonatal lupus syndromes.Rheum Dis Clin North Am 33: 267-285, vi.

72. Kowal C1, Degiorgio LA, Lee JY, Edgar MA, Huerta PT, et al. (2006) Human lupus autoantibodies against NMDA receptors mediate cognitive impairment. Proc Natl Acad Sci U S A 103: 19854-19859.

73. Husebye ES1, Sthoeger ZM, Dayan M, Zinger H, Elbirt D, et al. (2005) Autoantibodies to a NR2A peptide of the glutamate/NMDA receptor in sera of patients with systemic lupus erythematosus.Ann Rheum Dis 64: 1210-1213.

74. Lee LA1, Weston WL (1997) Cutaneous lupus erythematosus during the neonatal and childhood periods.Lupus 6: 132-138.

75. Glickstein JS1, Buyon J, Friedman D (2000) Pulsed Doppler echocardiographic assessment of the fetal PR interval.Am J Cardiol 86: 236-239.

76. Sonesson SE1, Salomonsson S, Jacobsson LA, Bremme K, Wahren-Herlenius $M(2004)$ Signs of first-degree heart block occur in one-third of fetuses of pregnant women with anti-SSA/Ro 52-kd antibodies.Arthritis Rheum 50: 1253-1261.

77. Zhao H1, Cuneo BF, Strasburger JF, Huhta JC, Gotteiner NL, et al. (2008) Electrophysiological characteristics of fetal atrioventricular block.J Am Coll Cardiol 51: 77-84

78. Gardiner HM1, Belmar C, Pasquini L, Seale A, Thomas M, et al. (2007) Fetal ECG: a novel predictor of atrioventricular block in anti-Ro positive pregnancies. Heart 93: 1454-1460. 
79. Johansen AS1, Herlin T (1998) [Neonatal lupus syndrome. Association with complete congenital atrioventricular block].Ugeskr Laeger 160: 2521-2525.

80. Saleeb S1, Copel J, Friedman D, Buyon JP (1999) Comparison of treatment with fluorinated glucocorticoids to the natural history of autoantibody-associated congenital heart block: retrospective review of the research registry for neonatal lupus.Arthritis Rheum 42: 2335-2345.

81. Yamada H1, Kato EH, Ebina Y, Moriwaki M, Yamamoto R, et al. (1999) Fetal treatment of congenital heart block ascribed to anti-SSA antibody: case reports with observation of cardiohemodynamics and review of the literature. Am J Reprod Immunol 42: 226-232.

82. Jaeggi ET1, Fouron JC, Silverman ED, Ryan G, Smallhorn J, et al. (2004) Transplacental fetal treatment improves the outcome of prenatally diagnosed complete atrioventricular block without structural heart disease.Circulation 110: $1542-1548$

83. Breur JM1, Visser GH, Kruize AA, Stoutenbeek P, Meijboom EJ (2004) Treatment of fetal heart block with maternal steroid therapy: case report and review of the literature.Ultrasound Obstet Gynecol 24: 467-472.

84. Friedman DM1, Kim MY, Copel JA, Llanos C, Davis C, et al. (2009) Prospective evaluation of fetuses with autoimmune-associated congenital heart block followed in the PR Interval and Dexamethasone Evaluation (PRIDE) Study. Am J Cardiol 103: 1102-1106

85. Rein AJ1, Mevorach D, Perles Z, Gavri S, Nadjari M, et al. (2009) Early diagnosis and treatment of atrioventricular block in the fetus exposed to maternal anti-SSA/Ro-SSB/La antibodies: a prospective, observational, fetal kinetocardiogram-based study.Circulation 119: 1867-1872.

86. Trucco SM1, Jaeggi E, Cuneo B, Moon-Grady AJ, Silverman E, et al. (2011) Use of intravenous gamma globulin and corticosteroids in the treatment of maternal autoantibody-mediated cardiomyopathy.J Am Coll Cardiol 57: 715723

87. Carpenter RJ Jr, Strasburger JF, Garson A Jr, Smith RT, Deter RL, et al. (1986) Fetal ventricular pacing for hydrops secondary to complete atrioventricular block.J Am Coll Cardiol 8: 1434-1436.

88. van der Leij JN1, Visser GH, Bink-Boelkens MT, Meilof JF, Kallenberg CG (1994) Successful outcome of pregnancy after treatment of maternal anti-Ro (SSA) antibodies with immunosuppressive therapy and plasmapheresis. Prenat Diagn 14: 1003-1007.

89. Wong JP1, Kwek KY, Tan JY, Yeo GS (2001) Fetal congenital complete heart block: prophylaxis with intravenous gammaglobulin and treatment with dexamethasone.Aust N Z J Obstet Gynaecol 41: 339-341.

90. Tsai YG1, Ou TY, Wang CC, Tsai MC, Yuh YS, et al. (2001) Intravenous gamma-globulin therapy in myocarditis complicated with complete heart block: Report of one case.Acta Paediatr Taiwan 42: 311-313.

91. Izmirly PM1, Kim MY, Llanos C, Le PU, Guerra MM, et al. (2010) Evaluation of the risk of anti-SSA/Ro-SSB/La antibody-associated cardiac manifestations of neonatal lupus in fetuses of mothers with systemic lupus erythematosus exposed to hydroxychloroquine.Ann Rheum Dis 69: 1827-1830.

92. Izmirly PM1, Costedoat-Chalumeau N, Pisoni CN, Khamashta MA, Kim MY, et al. (2012) Maternal use of hydroxychloroquine is associated with a reduced risk of recurrent anti-SSA/Ro-antibody-associated cardiac manifestations of neonatal lupus.Circulation 126: 76-82

93. Hutter D1, Silverman ED, Jaeggi ET (2010) The benefits of transplacental treatment of isolated congenital complete heart block associated with maternal anti-Ro/SSA antibodies: a review.Scand J Immunol 72: 235-241.
94. Mevorach D1, Elchalal U, Rein AJ (2009) Prevention of complete heart block in children of mothers with anti-SSA/Ro and anti-SSB/La autoantibodies: detection and treatment of first-degree atrioventricular block.Curr Opin Rheumatol 21: 478-482.

95. Groves AM1, Allan LD, Rosenthal E (1995) Therapeutic trial of sympathomimetics in three cases of complete heart block in the fetus.Circulation 92: 3394-3396.

96. Jiménez R, Figueras J, Botet F, Cruz M (1983) [Congenital heart block in a newborn infant born to a mother with lupus erythematosus].An Esp Pediatr 18: $510-514$.

97. Di Mauro A, Caroli Casavola V, Favia Guarnieri G, Calderoni G, Cicinelli E et al. (2013) Antenatal and postnatal combined therapy for autoantibody-related congenital atrioventricular block. BMC Pregnancy Childbirth 13:220.

98. Epstein AE, DiMarco JP, Ellenbogen KA, Estes NA III, Freedman RA, et al. (2008) ACC/AHA/HRS 2008 Guidelines for Device-Based Therapy of Cardiac Rhythm Abnormalities: a report of the American College of Cardiology/American Heart Association Task Force on Practice Guidelines (Writing Committee to Revise the ACC/AHA/NASPE 2002 Guideline Update for Implantation of Cardiac Pacemakers and Antiarrhythmia Devices): developed in collaboration with the American Association for Thoracic Surgery and Society of Thoracic Surgeons. Circulation 117:e350-408.

99. Vardas PE, Auricchio A, Blanc JJ, Daubert JC, Drexler H, et al (2007) Guidelines for cardiac pacing and cardiac resynchronization therapy: The Task Force for Cardiac Pacing and Cardiac Resynchronization Therapy of the European Society of Cardiology. Developed in collaboration with the European Heart Rhythm Association. Eur Heart J 28:2256-2295.

100. Brignole M, Auricchio A, Baron-Esquivias G, Bordachar P, Boriani G, et al (2013) ESC Guidelines on cardiac pacing and cardiac resynchronization therapy: the Task Force on cardiac pacing and resynchronization therapy of the European Society of Cardiology (ESC). Developed in collaboration with the European Heart Rhythm Association (EHRA). Eur Heart J 34:22812329 .

101. Tops LF1, Suffoletto MS, Bleeker GB, Boersma E, van der Wall EE, et al. (2007) Speckle-tracking radial strain reveals left ventricular dyssynchrony in patients with permanent right ventricular pacing.J Am Coll Cardiol 50: 1180-1188.

102. Yasuda K1, Hayashi G, Ohuchi H, Ono Y, Yutani C, et al. (2005) Dilated cardiomyopathy after pacemaker implantation in complete heart block.Pediatr Int 47: 121-125.

103. Taylor-Albert E1, Reichlin M, Toews WH, Overholt ED, Lee LA (1997) Delayed dilated cardiomyopathy as a manifestation of neonatal lupus: case reports, autoantibody analysis, and management.Pediatrics 99: 733-735.

104. Cruz RB1, Viana VS, Nishioka SA, Martinelli-F M, Bonfa E (2004) Is isolated congenital heart block associated to neonatal lupus requiring pacemaker a distinct cardiac syndrome?Pacing Clin Electrophysiol 27: 615-620.

105. Izmirly PM1, Saxena A, Kim MY, Wang D, Sahl SK, et al. (2011) Maternal and fetal factors associated with mortality and morbidity in a multi-racial/ ethnic registry of anti-SSA/Ro-associated cardiac neonatal lupus.Circulation 124: 1927-1935

106. Eliasson H1, Sonesson SE, Sharland G, Granath F, Simpson JM, et al. (2011) Isolated atrioventricular block in the fetus: a retrospective, multinational, multicenter study of 175 patients.Circulation 124: 1919-1926.

107. Martin V1, Lee LA, Askanase AD, Katholi M, Buyon JP (2002) Long-term followup of children with neonatal lupus and their unaffected siblings.Arthritis Rheum 46: 2377-2383. 